\title{
Carica Papaya as a Mucosa Enhancer in Gastric Lesion after Ethanol Administration in Adult Male Wistar Rats
}

\author{
Okesina $\mathrm{AA}^{1 *}$, Mohammed $\mathrm{AA}^{2}$, Buhari MO and Caxton Martins $\mathrm{EA}^{3}$ \\ ${ }^{1}$ Department of Anatomy, University of Gitwe, Nigeria \\ ${ }^{2}$ Department of Human Anatomy Kampala International University Western Campus Ishaka Bushenyi, Uganda \\ ${ }^{3}$ Department of Anatomy, University of Ilorin, Nigeria
}

Submission: September 12, 2017; Published: November 27, 2017

"Corresponding author: Okesina Akeem Ayodeji, Department of Anatomy, University of Gitwe, Rwanda, Nigeria, Tel: 08033725777;

Email: akeemokesina@yahoo.com/akeemokesina@gmail.com

\begin{abstract}
This study was performed to determine the regenerative potential of Cariaca papaya leaves (CPL) on $50 \%$ ethanol induced gastric lesions. It involves histological studies, including Haemotoxylin and Eosin, Periodic Acid Schiff (PAS), Aldehyde Fuchsin, and Van Geison's stain, in the stomach of male adult Wistar rats. Twenty-four male adult Wistar rats weighing 180-220g were used in this study, with the animals divided into three groups ( $n=8$ per group). The control group (group $A ; n=8$ ) received phosphate buffered saline orally, with the aid of a cannula. 1 ml of $50 \%$ ethanol was administered orally, by a cannula, to produce the gastric lesion in group $B(\mathrm{n}=8)$. And in the group C, $500 \mathrm{mg} / \mathrm{kg} \mathrm{body} \mathrm{weight}$ of paw paw leaf extract was administered orally, with a cannula, twelve hours after ethanol administration to the rats. This experiment lasted for twenty one consecutive days.
\end{abstract}

Histological studies showed the rat's gastric mucosa to be eroded, following ethanol administration; and after the treatment with CPL, some form of regeneration was observed.

Keywords: Caricapapaya; Ethanol; Mucosa; Hematoxylin

\section{Introduction}

Carica papaya (CP) is a member of the family Caricaceae, the third most important horticultural crop after citrus and plantain in Nigeria [1-5]. CP is a dual or multi-purpose, early bearing, space conserving, herbaceous crop, is widely acclaimed, despite its susceptibility to natural enemies [4]. In some islands of the West

Indies, it is known as pawpaw [1]. Originally from Southern Mexico, Central America and Northern South America, the papaya is now cultivated in most countries with tropical climate like Malaysia and the West Indies. Caricapapaya leaf (CPL) is used for food or as medication in folk medicine. It is consumed as a vegetable by the Malay community in Malaysia and by the natives of the East Indies. Traditionally, the leaf extract was used as a tonic for the heart, an analgesic and in the treatment of stomach ache [2]. The extract is also known to have antioxidant properties [6], but there are no scientific reports on the protective effect of this extract on alcohol induced acute gastric damage. Gastric ulcers, one of the most widespread disease states, are believed to be due to an imbalance between acid and pepsin along with weakness of the mucosal barrier. There are many products used for the treatment of gastric ulcers, such as antacids, proton pump inhibitors or antihistaminic agents, but most of these drugs produce several adverse reactions. Thus, there is a need for more effective and less toxic anti-ulcer.

\section{Materials and Method}

\section{Animals}

24 adult male Wistar rats weighing 190-210g, which were purchased from Animal house University of Ilorin were used in this project work. They were each weighed and randomly assigned to three groups (A, B and C). They were kept and maintained under standard laboratory conditions of temperature, humidity, and light. They were allowed free access to standard laboratory diet pellets and water liberally. All animals were fasted 24 hours before the commencement of the experiment. Ethical approval was obtained from the University of Ilorin ethical review committee. 


\section{Advanced Research in Gastroenterology \& Hepatology}

\section{Plant Material and Extract Preparation}

Leaves of Carica papaya leaves were collected within the premises of College of Medicine University of Ilorin Kwara State Nigeria. Identification of plant was carried out in the department of Botany University of Ilorin. A large quantity of leaves were collected, washed clean with water, air dried and reduced to powder using a mortar and pestle. Powdered leaves of plant weighing $100 \mathrm{~g}$ was mixed with 1litre of $70 \%$ ethanol and the mixture was left for 24 hours, mixture was filtered and the filtrate was concentrated in a water bath (maintained at $60 \pm 0.2{ }^{\circ} \mathrm{C}$ ) to yield $15 \mathrm{~g}$ of dark green solid extract. The solid extract was stored in a refrigerator.

\section{Treatment}

Group A received oral phosphate buffered saline (PBS) and served as control. Group B (Ethanol) received $1.0 \mathrm{ml}$ of $50 \%$ ethanol orally every 12 hours. Group C (Ethanol+CPL) received pawpaw leaf extract $(500 \mathrm{mg} / \mathrm{kg}$ ) orally 12 hours after $1.0 \mathrm{ml} 50 \%$ ethanol for 21 consecutive days. 24 hours after the last administration the animals were sacrificed following cervical dislocation and the stomach was excised. The stomach of all the sacrificed animals were fixed in $10 \%$ formol saline and processed for histological studies. Serial paraffin sections at $5 \mu \mathrm{m}$ thickness was obtained on a Leitz rotary microtome and stained with Haematoxylin and Eosin (H \& E), Van geison's stain for elastic tissues, Aldehyde Fuchsin, Periodic Acid Schiff for brush borders.

\section{Results}

\section{Physical observation}

During the time of this investigation the animals were carefully observed as regards to feeding and physical appearance. Feeding in the animals was not altered as they were still feeding normally. Feeds were weighed before it was given to the animals and the quantity left in the feeding though, if any, was measured. The eyes remained pinkish and also the faces were observed to be normal that is dark brown and solid but not too dry.

\section{Weight of the animals}

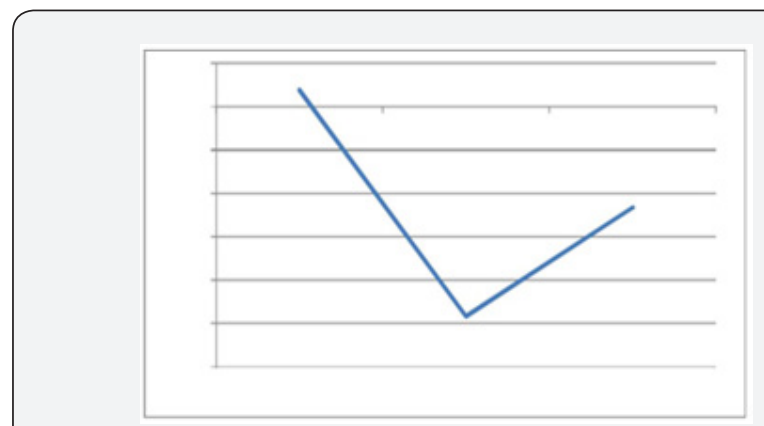

Figure 1: The average percentage weight change in the 24 experimental animal $(n=8)$ at the end of the experiment.

The animals were weighed with an electronic weighing balance (SALTUN@EK5055Max) during and after the experiment, and the average weight of the three groups (Group A which is the PBS control group, group $B$ which is the Ethanol treated group and group $\mathrm{C}$ which is the Ethanol+CPL treated group) in percentage were compared at the end of the experiment. After 21 days of administration, the weight of the rats were noted and measured in percentage weight change. The weight of the PBS control group increased by $0.38 \%$, that of ethanol group was reduced by $4.83 \%$ and the CPL treated group was reduced by $2.33 \%$ (Figure 1 ).

\section{Histological Observations}

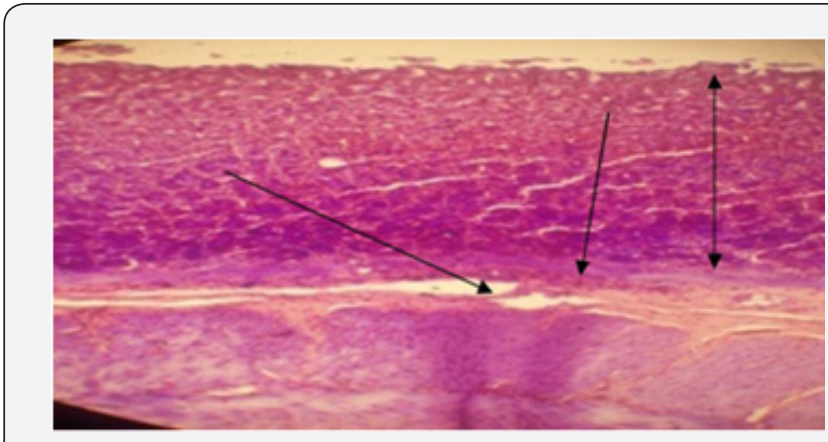

Figure 2: Photomicrograph of rat stomach (PBS control), Aldehyde fuchsin stain.M (mucosa) MM(muscularismucosa), EF(elastic fibres), S(submucosa). X320.

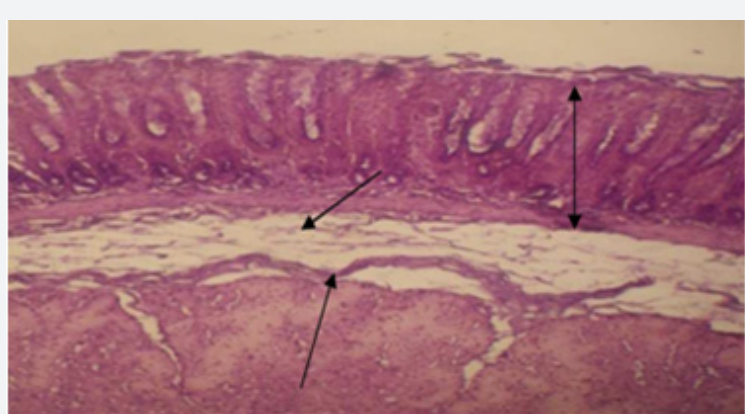

Figure 3: Photomicrograph of rat stomach (ethanol treated) Aldehyde fuchsin stain.M(mucosa) MM(muscularis mucosa), EF(elastic fibres), S(submucosa).X320.

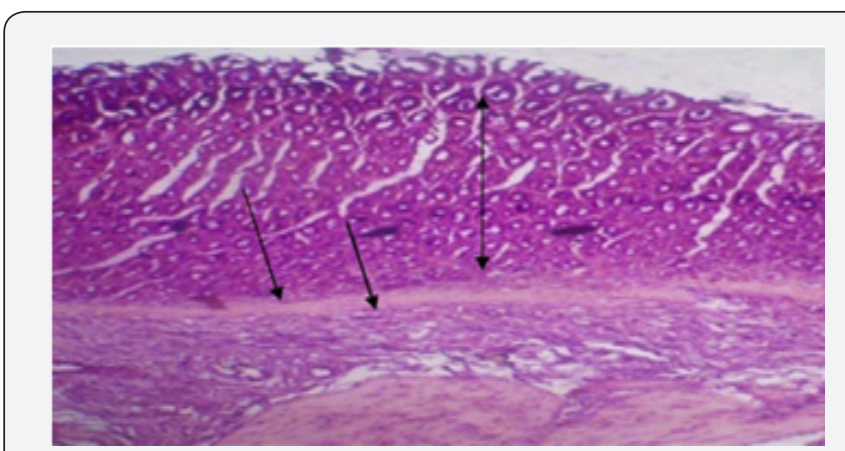

Figure 4: Photomicrograph of rat stomach (CPL treated), Aldehyde Fuchsin Stain.M(mucosa) MM(muscularis mucosa), EF(elastic fibres), S(submucosa). X320.

Regenerative effect was observed on $1 \mathrm{ml}$ of $50 \%$ ethanol induced gastric lesion in rats after the treatment with $500 \mathrm{mg} / \mathrm{kg}$ of CPL. The CPL treated groups showed remarkable changes as compared to the ethanol treated animals. And these changes produced by CPL treated groups are comparable to PBS control groups. These results showed that $500 \mathrm{mg} / \mathrm{kg}$ of CPL had a regenerative effect against the gastric lesion caused by ethanol (Figure 2-13). 


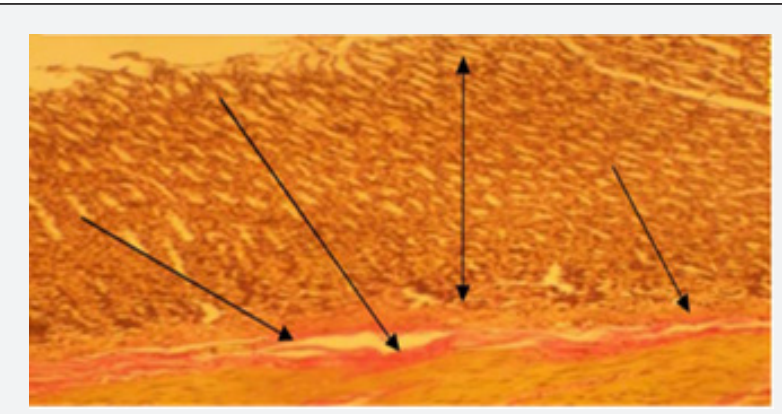

Figure 5: Photomicrograph of rat stomach,(PBS control) Van Geison's Stain M(mucosa) MM(muscularis mucosa) $\mathrm{S}$ (submucosa) CF (collagen fibers). X320.

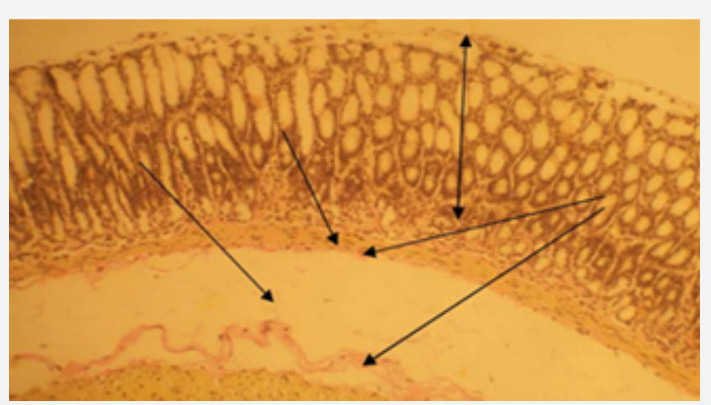

Figure 6: Photomicrograph of rat stomach,(ethanol treated) Van Geison's Stain M(mucosa) MM(muscularis mucosa) S(submucosa) CF (collagen fibers). X320.

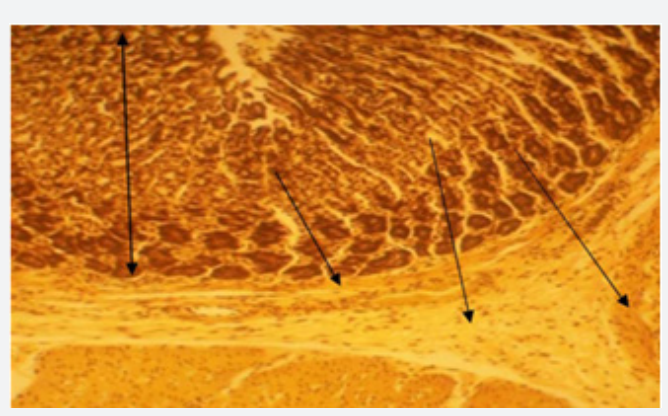

Figure 7: Photomicrograph of rat stomach,(CPL treated) Van Geison's Stain M(mucosa) MM(muscularis mucosa) S(submucosa) CF (collagen fibers). X320.

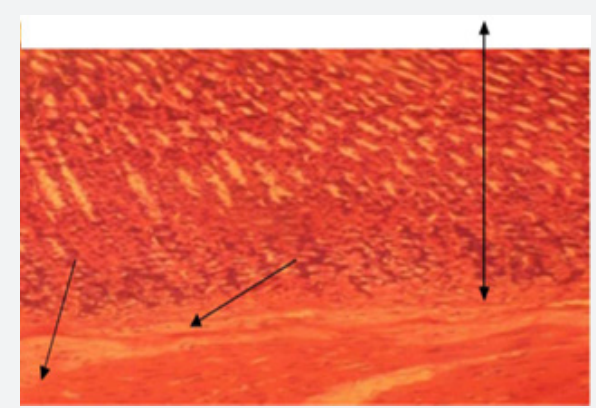

Figure 8: Photomicrograph of rat stomach, (PBS control) H \& E Stain M (mucosa) MM(muscularis mucosa) S(submucosa). $\mathrm{X} 320$.

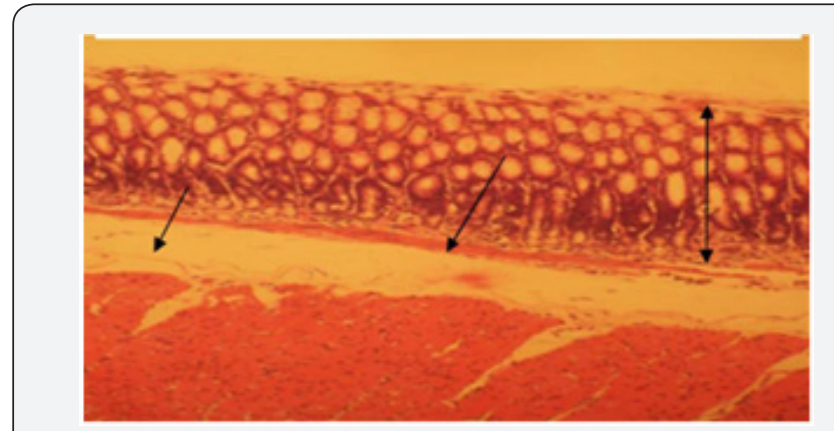

Figure 9: Photomicrograph of rat stomach,(ethanol treated)H \& $\mathrm{E}$ Stain $\mathrm{M}$ (mucosa) $\mathrm{MM}$ (muscularis mucosa) S(submucosa). X320.

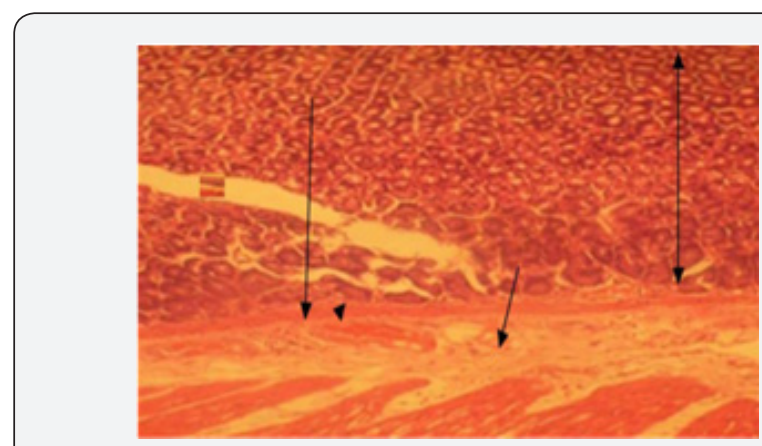

Figure 10: Photomicrograph of rat stomach,(PBS treated)H \& E Stain $\mathrm{M}$ (mucosa) $\mathrm{MM}$ (muscularis mucosa) $\mathrm{S}$ (submucosa). X320.

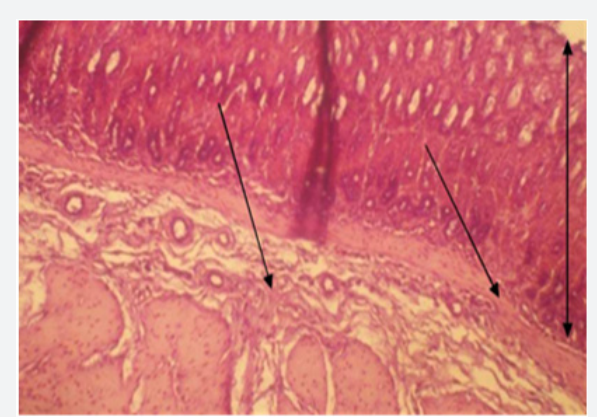

Figure 11: Photomicrograph of rat stomach,(PBS control) PAS Stain M(mucosa) MM(muscularis mucosa) S(submucosa) GG (gastric glands). X320.

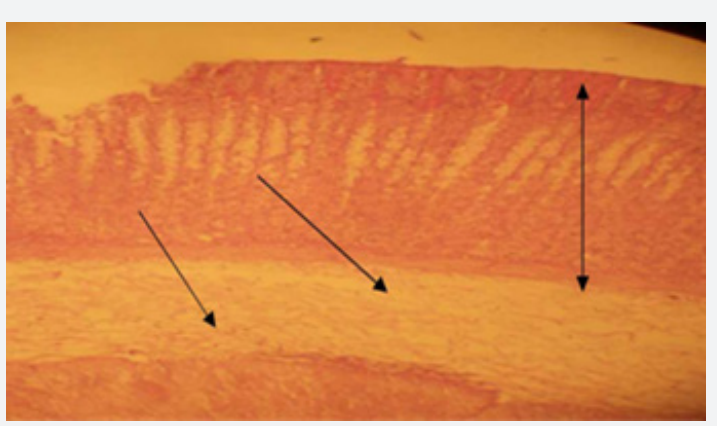

Figure 12: Photomicrograph of rat stomach, (ethanol treated) PAS Stain M(mucosa) MM(muscularis mucosa) S(submucosa) GG (gastric glands). X320. 


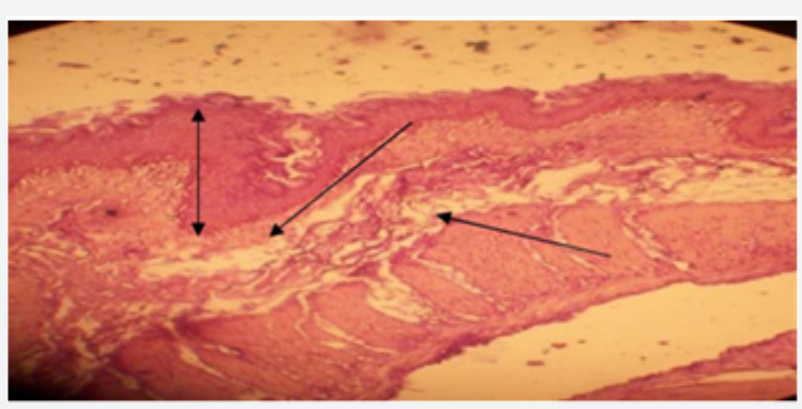

Figure 13: Photomicrograph of rat stomach,(ethanol treated) PAS Stain M(mucosa) MM(muscularis mucosa) S(submucosa) $\mathrm{GG}$ (gastric glands). X320.

\section{Discussion}

In this study the regenerative potential of CPL was investigated in ethanol induced gastric lesion on adult male Wistar rats. It has been demonstrated that a single dose $(500 \mathrm{mg} / \mathrm{kg})$ of $\mathrm{CPL}$ aqueous extract is able to protect the rat gastric mucosa against haemorrhagic lesions produced by alcohol [3]. This dose was chosen after preliminary assessment using a wide dose range of this extract. Oral administration of ethanol in rat is noxious for the stomach, affecting the gastric mucosa by disrupting its barrier and provoking pronounced micro/macrovascular changes a few minutes after its administration

During the experimental period, it was noted that after each ethanol administration the physical activity of the rats increased immediately, and after some time they became slow in action. Both the ethanol and CPL treated groups did not consume their feeds as much as the PBS treated control group and this must be responsible for the loss in weight of both groups.

After 21 days of administration, the weight of the rats was noted and measured in percentage weight change. The weight of the PBS control group increased by $0.38 \%$, that of ethanol group was reduced by $4.83 \%$ and the CPL treated group was reduced by $2.33 \%$.

Histological observations made after viewing the tissue slides under the (Olympus) light microscope, revealed three layers of the rat stomach in this work. Four different stains were used to study the various structures of the gastric tissues of three different rat stomachs. The three rat stomachs were divided into PBS control, Ethanol treated and CPL treated. And four stains were used in this histological study; Aldehyde fuchsin, Van Geison, H\&E and PAS. Aldehyde Fuchsin in PBS control was used to stain for elastic fibres present in the mucosa layer. It was densely stained in PBS control, faintly stained in Ethanol treated and also in CPL treated it was slight densely stained.

Van Geison was used to stain for collagen fibres which are found around the muscularis mucosa which stains as red. The red stain was in form of as a thick line in PBS control while in ethanol treated, it was a thin line stain. It was also stained thick in CPL treated. $\mathrm{H}$ \& E stain was used to investigate the gastric mucosa layer. In PBS control it was densely stained but not densely stained in ethanol treated, showing the level of erosion in the mucosa and in the CPL treated it was densely stained showing level of regeneration. PAS used to Show the brush boarders, (the mucosubstances) i.e the gastric glands that produce mucous secreting cells which are carbohydrate in nature.

PAS positive magenta colour was seen in PBS control, but was not seen in ethanol treated because it was faintly stained. The magenta colour was also seen in CPL treated. When comparing the three groups, regenerative effect was observed on $1 \mathrm{ml}$ of $50 \%$ ethanol induced gastric lesion in rats after CPL treatment, which showed remarkable changes as compared to the ethanol treated animals. And these changes produced by CPL treated groups are comparable to PBS control groups. These changes showed that 500 $\mathrm{mg} / \mathrm{kg}$ of CPL had a regenerative effect against the gastric lesion caused by ethanol. In summary, the results demonstrated that CPL treatment exerts regenerative effects in ethanol-induced gastric lesion in rats.

\section{References}

1. Fermin G, Tennant P, Gonsalves C, Lee D, Gonsalves D (2005) Comparative development and impact of transgenic papayas in Hawaii, Jamaica and Venezuela. Methods Mol Biol 286: 399-430.

2. Giove Nakazawa RA (1996) Traditional medicine in the treatment of enteroparasitosis. Rev Gastroenterol Peru 16(3): 197-202.

3. Gonthier B, Signorin-Allibe N, Soubeyran A, Eysseric H, Lamarche F, et al. (2004) Ethanol can modify the effects of certain free radical generating system on astrocytes. Alcohol Clin Exp Res 28(4): 526-534.

4. Hernandez CN, Valle-Mora J, Santiesteban-Hernandee A, BelloMendoza R (2007) Comparative ecological risks of pesticides used in plantation production of papaya: application of the SYNOPS indicator. Sci Total Environ 381(1-3): 112-125.

5. Oluma HOA, Amuta EU (1999) Corynespora Cassiacola leaf spot of pawpaw (caricapapya L) in Nigeria. Mycopathologia 145(1): 23-27.

6. Rahmat A, Abu Bakar MF, Faezah N, Hambali Z (2004) The effect of consumption of guava (Psidium guajaya) or Carica papaya on total antioxidant and lipid profile in normal male youth. Asia Pac J Clin Nutr 13: S106. 


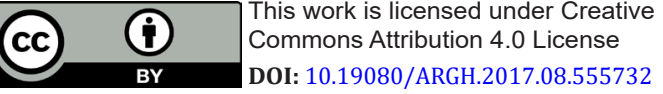

\section{Your next submission with Juniper Publishers will reach you the below assets}

- Quality Editorial service

- Swift Peer Review

- Reprints availability

- E-prints Service

- Manuscript Podcast for convenient understanding

- Global attainment for your research

- Manuscript accessibility in different formats

( Pdf, E-pub, Full Text, Audio)

- Unceasing customer service

Track the below URL for one-step submission https://juniperpublishers.com/online-submission.php 